\title{
ESTRUTURA, DIVERSIDADE E HETEROGENEIDADE DE UMA FLORESTA OMBRÓFILA MISTA ALTOMONTANA EM SEU EXTREMO NORTE DE DISTRIBUIÇÃO (MINAS GERAIS)
}

\author{
STRUCTURE, DIVERSITY AND HETEROGENEITY OF AN UPPER MONTANE MIXED \\ OMBROPHYLOUS FOREST IN ITS EXTREME NORTHERN DISTRIBUTION (MINAS GERAIS \\ STATE)
}

\begin{abstract}
Lucas Deziderio Santana ${ }^{1}$ José Hugo Campos Ribeiro ${ }^{2}$ Natalia Macedo Ivanauskas ${ }^{3}$ Fabrício Alvim Carvalho ${ }^{4}$
\end{abstract}

\section{RESUMO}

A Floresta Ombrófila Mista é uma das fitofisionomias mais ameaçadas do Brasil. Estima-se que apenas cerca de 3\% da cobertura original desta formação florestal tenham restado. Em Minas Gerais, os remanescentes destas florestas com araucária são raros, restringindo-se principalmente ao Sul do estado. $\mathrm{O}$ trabalho objetivou avaliar a estrutura, a diversidade e a heterogeneidade de espécies do estrato arbóreo de uma Floresta Ombrófila Mista Altomontana em seu extremo norte de distribuição, Minas Gerais - Brasil. O presente estudo foi conduzido no Parque Estadual da Serra do Papagaio (PESP), que engloba o único remanescente de floresta com araucária em uma Unidade de Conservação (UC) de proteção integral em Minas Gerais. Foram alocadas na área 25 parcelas de 20 x $10 \mathrm{~m}(0,5$ ha) e toda vegetação arbustiva-arbórea com DAP $\geq 4,8 \mathrm{~cm}$ foi mensurada, identificada e teve a altura estimada. Amostramos 1.158 indivíduos, pertencentes a 41 espécies, 28 gêneros e 22 famílias. Foi observada uma comunidade com forte concentração dos Valores de Importância (VI) nas três primeiras espécies (Podocarpus lambertii, Araucaria angustifolia e Myrceugenia bracteosa), que juntas somam 52,74\% do VI total. A área basal total da comunidade foi de $30,82 \mathrm{~m}^{2}\left(61,65 \mathrm{~m}^{2} \cdot \mathrm{ha}^{-1}\right)$, estando entre uma das maiores já registradas para a Floresta Ombrófila Mista. $\mathrm{O}$ índice de diversidade de espécies de Shannon $\left(\mathrm{H}^{\prime}=2,67\right.$ nats.ind $\left.^{-1}\right)$ está na faixa observada em outros estudos na formação Altomontana. Por meio de análises multivariadas, constatou-se baixa heterogeneidade florística na comunidade, já que as principais espécies, representadas em termos de densidade na matriz de análise, estão bem distribuídas por toda a floresta. O estudo descreve uma comunidade bem estruturada e com grande acúmulo de biomassa, mostrando a relevância da UC para a preservação desta importante, rara e ameaçada fitofisionomia em Minas Gerais.

Palavras-chave: Fitossociologia; Floresta com Araucária; Floresta Atlântica; Unidade de Conservação.

\begin{abstract}
The Mixed Ombrophylous Forest is one of the most threatened forest ecosystems in the country and it is estimated that only about $3 \%$ of the original covering of this vegetation type has remained. In Minas Gerais state, these remaining forests are rare, restricted mainly to the south of the state. This study aimed to evaluate the structure, diversity and heterogeneity of tree layer species of a Mixed Ombrophylous Forest in its most extreme northern distribution (Minas Gerais state, Brazil). The study was conducted in Parque Estadual

1 Biólogo, MSc., Doutorando em Engenharia Florestal, Laboratório de Ecologia Vegetal, Universidade Federal de Lavras, Avenida Doutor Sylvio Menicucci, 1001, Kennedy, CEP 37200-000, Lavras (MG), Brasil. lucasdeziderio01@gmail.com

2 Biólogo, Dr., Professor do Instituto Federal de Educação, Ciência e Tecnologia do Sudeste de Minas Gerais, CEP 36884-036, Muriaé (MG) Brasil. Brasil.jhugocampos@gmail.com

3 Engenheira Agrônoma, Dr ${ }^{a}$., Pesquisadora Científica do Instituto Florestal do Estado de São Paulo, Divisão de Dasonomia, Rua do Horto, 931, Horto Florestal, CEP 02377-000, São Paulo (SP), Brasil. nivanaus@yahoo.com. br

4 Biólogo, Dr., Professor do Departamento de Botânica, Universidade Federal de Juiz de Fora, Rua José Lourenço Kelmer, s/n, Martelos, CEP 36036-330, Juiz de Fora (MG), Brasil. fabricio.alvim@gmail.com
\end{abstract}

Recebido para publicação em 18/07/2015 e aceito em 16/03/2017

Ci. Fl., v. 28, n. 2, abr. - jun., 2018 
da Serra do Papagaio (PESP), which includes the only remaining of araucaria forest in a full protection Conservation Unit (CU) in Minas Gerais state. We allocated in the area 25 permanent plots of $20 \mathrm{~m} \times 10 \mathrm{~m}$ $(0.5 \mathrm{ha})$ and every shrub and tree vegetation with $\mathrm{DBH} \geq 4.8 \mathrm{~cm}$ was measured, identified and the height was estimated. We measured 1,158 individuals, belonging to 41 species, 28 genera and 22 families. It was observed a community with a strong concentration of the importance values (IV) in the first three species (Podocarpus lambertii, Araucaria angustifolia and Myrceugenia bracteosa), that together add up 52.74\% of total IV of the community. The basal area of the community was $30.82 \mathrm{~m}^{2}\left(61.65 \mathrm{~m}^{2}\right.$.ha-1), being one of the largest ever registered for Mixed Ombrophylous Forests. The Shannon species diversity index $\left(\mathrm{H}^{\prime}\right.$ $=2.67$ nats.ind $^{-1}$ ) was in the range observed in other studies of Upper Montane Mixed Ombrophylous Forest. Multivariate analysis indicated a low floristic heterogeneity in the community; however, this low heterogeneity occurred because the main species in terms of density are also the most frequent and are distributed throughout the forest. The study shows a well-structured community with large accumulation of biomass, showing the importance of the conservation unit for the preservation of this important, rare and threatened vegetation type in Minas Gerais state.

Keywords: Araucaria forest; Atlantic forest; Conservation Unit; Phytosociology.

\section{INTRODUÇÃO}

A Floresta Ombrófila Mista (FOM) é uma das fitosionomias mais ameaçadas no Brasil. Algumas estimativas apontam que apenas cerca de $3 \%$ da cobertura original desta formação florestal tenham restado (BAUERMANN; BEHLING, 2009). A redução drástica desta fitofisionomia nas últimas décadas é reflexo da intensa pressão exploratória de sua espécie típica, Araucaria angustifolia (Bertol.) Kuntze (KOCH; CORRÊA, 2010; CARLUCCI et al., 2011). A situação é preocupante, pois poucos remanescentes de floresta com araucária se encontram em unidades de conservação de proteção integral, a maior parte é encontrada no estado de Santa Catarina (KERSTEN; BORGO; GALVÃO, 2015).

No fim da última era glacial, a distribuição da Floresta Ombrófila Mista se estendia até o nordeste brasileiro (BEHLING; PILLAR, 2007; KOCH; CORRÊA, 2010). Contudo, quando a temperatura da Terra começou a elevar e o sul do país tornou-se mais úmido, esta formação vegetacional deslocou-se principalmente para o Planalto Meridional Brasileiro, enquanto algumas populações ficaram isoladas em locais de grandes altitudes na Serra da Mantiqueira e na Serra do Mar, em que o clima frio e úmido permitiu sua existência até os dias atuais (BAUERMANN; BEHLING, 2009; KOCH; CORRÊA, 2010; CARLUCCI et al., 2011; KERSTEN; BORGO; GALVÃO, 2015).

Atualmente, a Floresta Ombrófila Mista tem seu limite sul de distribuição no norte do estado do Rio Grande do Sul; a oeste ultrapassa o Rio Paraná, alcançando a província de Missiones na Argentina e algumas porções no Paraguai e tem seu limite sul de distribuição no norte do Estado do Rio Grande do Sul (IBGE, 2012; KERSTEN; BORGO; GALVÃO, 2015). Contudo, seu limite extremo ao norte ainda é controverso. Alguns trabalhos apontam as serras próximas a $20^{\circ} \mathrm{S}$ como sendo este limite. No entanto, esta fitofisionomia já não é mais vista na localidade. Desta forma, o remanescente de Floresta Ombrófila Mista mais ao norte conhecido encontra-se na Serra da Mantiqueira em Minas Gerais, no Parque Estadual da Serra do Papagaio, ocupando os fundos de vale, em altitudes superiores a 1.500 m (KERSTEN; BORGO; GALVÃO, 2015).

Transpondo-se a Serra do Mar, a Serra da Mantiqueira forma o segundo degrau do Planalto Brasileiro (ALMEIDA; CARNEIRO, 1998). Abrange parte dos estados de São Paulo, Rio de Janeiro, Minas Gerais e Espírito Santo e é considerada uma das mais importantes cadeias de montanhas do sudeste brasileiro (COSTA; HERMANN, 2006). Devido à elevada riqueza de espécies da fauna e flora e ao alto grau de endemismo, esta cadeia montanhosa foi considerada como área de importância biológica especial (COSTA; HERMANN, 2006) e listada entre as de maior importância em biodiversidade do mundo (LE SAOUT et al., 2013).

Embora tenham ocorrido vários avanços científicos nos últimos anos, estudos sobre a flora ao longo de toda a extensão da floresta com araucária ainda são poucos, principalmente os quantitativos (KERSTEN; BORGO; GALVÃO, 2015). Através de uma compilação de dados, Kersten, Borgo e Galvão (2015) verificaram que, até o ano de 2013, somente 75 artigos quantitativos sobre a Floresta Ombrófila 
Mista constavam no banco de dados de periódicos científicos nacionais, além de um na Argentina. Porém, a maioria dos estudos eram da região Sul do Brasil, principalmente no estado do Paraná (46 artigos). Já na região Sudeste, foram publicados trabalhos apenas em São Paulo (SOUZA et al., 2012; RIBEIRO et al., 2013; POLISEL et al., 2014), apesar da floresta com araucária também estar presente nos estados de Minas Gerais e Rio de Janeiro.

Sabendo das ameaças que a Floresta Ombrófila Mista vem sofrendo e considerando-se a carência de estudos quantitativos nesta fitofisionomia para a região Sudeste, o presente trabalho teve como objetivo avaliar a estrutura, diversidade e heterogeneidade de espécies do estrato arbóreo de uma Floresta Ombrófila Mista Altomontana em seu extremo norte de distribuição (Minas Gerais - Brasil).

\section{MATERIAL E MÉTODOS}

\section{Área de estudo}

O trabalho foi conduzido em um trecho de Floresta Ombrófila Mista Altomontana (IBGE, 2012) localizado em uma Unidade de Conservação de proteção integral denominado Parque Estadual da Serra do Papagaio (PESP). O PESP está localizado na região Sul de Minas Gerais (Brasil) na Serra da Mantiqueira, com área total de 22.917 hectares entre os municípios de Aiuruoca, Alagoa, Baependi, Itamonte e Pouso Alto, próximo as coordenadas $22^{\circ} 08^{\circ} 34.95^{\prime \prime S}$ e $44^{\circ} 43^{\prime} 43.21^{\prime \prime W}$ (INSTITUTO ESTADUAL DE FLORESTAS, 2009). Além disso, a região sul do parque interliga-se geograficamente com o Parque Nacional (PARNA) do Itatiaia, compondo um conjunto montanhoso contínuo legalmente preservado, essas duas áreas protegem um dos maiores fragmentos de vegetação nativa da Serra da Mantiqueira (INSTITUTO ESTADUAL DE FLORESTAS, 2015). Le Saout et al. (2013) ressaltam que a APA da Serra da Mantiqueira, em conjunto com o PARNA do Itatiaia, estão entre os dez lugares de maior importância para a conservação da biodiversidade do planeta, por abrigarem alta diversidade, além de elevado número de espécies ameaçadas de extinção.

De acordo com a classificação de Köppen (KOTTEK et al., 2006) a região possui um clima do tipo Cwb, com inverno frio e seco, e chuvas elevadas no verão, podendo ocorrer geadas em algumas épocas do ano. A precipitação média anual situa-se próxima a $1.568 \mathrm{~mm}$, além da umidade advinda da chuva horizontal. Há uma sazonalidade da chuva ao longo do ano, com cerca de $80 \%$ da precipitação concentrada no período de outubro a março. Porém, não se verifica mês totalmente seco na região (zero de precipitação). A temperatura média anual fica em torno de $20,6^{\circ} \mathrm{C}$. As temperaturas mínimas registradas no inverno estão entre $0^{\circ} \mathrm{C}$ e $10^{\circ} \mathrm{C}$. O verão é ameno e com pluviosidade elevada. Entretanto, os dias mais quentes podem registrar temperaturas próximas dos $30^{\circ} \mathrm{C}$ (INSTITUTO ESTADUAL DE FLORESTAS, 2009; BAEPENDI, 2015).

No parque a floresta com araucária distribui-se principalmente nos fundos de vale, sendo os interflúvios ocupados por campos naturais. Os solos predominantementes nesta região são os Cambissolos Húmicos e Cambissolos Hísticos, em altitudes entre 1.600 e 1.700 m.s.m. (SILVA; VIANA; MOTA, 2008; INSTITUTO ESTADUAL DE FLORESTAS, 2009). O trecho florestal estudado situa-se na zona rural do município de Baependi - Minas Gerais e acompanha o ribeirão Santo Agostinho por aproximadamente $5 \mathrm{~km}$ de extensão, geralmente em faixa estreita de $40 \mathrm{~m}$ em cada margem, mas em alguns pontos atinge cerca de $100 \mathrm{~m}$ de largura. Apresenta dossel de Araucaria angustifolia com indivíduos de até $30 \mathrm{~m}$ de altura e um segundo estrato composto principalmente por Podocarpus lambertii (variando de 10 a $15 \mathrm{~m}$ de altura) (FURTADO; MENINI NETO, 2016).

\section{Amostragem e coleta dos dados}

No remanescente florestal foram alocadas aleatoriamente 25 parcelas permanentes de $20 \times 10 \mathrm{~m}$, totalizando 0,5 ha de área amostrada. Todos os indivíduos arbustivo-arbóreos vivos com diâmetro na altura do peito (DAP) $(1,30 \mathrm{~m}) \geq 4,8 \mathrm{~cm}$ foram mensurados, marcados com placas de alumínio e identificados até o nível de espécie quando possível. O diâmetro foi medido com auxílio de uma fita métrica e a altura foi estimada para todos os indivíduos. Os indivíduos que apresentavam ramificações a partir da base do caule foram incluídos quando pelo menos uma das ramificações obedecia ao critério de inclusão, sendo, então, 
anotado o diâmetro de todas as ramificações para o cálculo da área basal. Os indivíduos mortos ainda em pé dentro das parcelas com DAP $\geq 4,8 \mathrm{~cm}$ também foram mensurados. O estudo foi realizado de setembro de 2014 a junho de 2015.

O material botânico coletado foi identificado utilizando-se literatura especializada (chaves de identificação, descrição de espécies, etc), consulta a especialistas e comparação através da coleção do herbário Leopoldo Krieger (CESJ) da Universidade Federal de Juiz de Fora (UFJF). A classificação das famílias botânicas seguiu a proposta do Angiosperm Phylogeny Group IV (2016) e Pteridophyte Phylogeny Group (2016). A sinonímia das espécies foi checada na Lista de Espécies da Flora do Brasil 2020 (THE BRAZIL FLORA GROUP, 2015).

\section{Análise dos dados}

Os parâmetros estruturais das espécies foram analisados de acordo com Kent e Coker (1992), obtendo-se os seguintes parâmetros: área basal (AB), dominância relativa (DoR), densidade absoluta e relativa (DA e DR), frequência absoluta e relativa (FA e FR) e Valor de Importância (VI).

Histograma de distribuição de diâmetro, com intervalo fixo de $5 \mathrm{~cm}$, foi elaborado para o somatório das áreas basais da comunidade. O índice de diversidade de Shannon $\left(\mathrm{H}^{\prime}\right)$, calculado com base no logaritmo natural, foi utilizado para analisar a diversidade de espécies da comunidade. O índice de equabilidade de Pielou (J'), baseado em H', foi utilizado para estimativa da uniformidade da comunidade (MAGURRAN, 2012). Além disso, foi elaborada uma relação entre densidade $\left(\mathrm{N}^{\circ}\right.$ ind.ha-1) e área basal $\left(\mathrm{m}^{2}\right.$.ha-1) de estudos feitos em fragmentos de floresta com araucária no Brasil, para verificar quais florestas estão bem estruturadas e em qual faixa altitudinal e em qual estado estão localizadas.

Análises multivariadas foram aplicadas para checar a heterogeneidade florística em nível local, analisando-se de forma integrada os dados de espécies em relação às unidades amostrais (FELFILI et al., 2011). Para a análise da similaridade florística entre as parcelas, o método de classificação utilizado foi a Análise de Agrupamento Hierárquico (cluster), através do método de agrupamentos de médias não ponderadas (UPGMA). Foi utilizado nesta análise, o coeficiente quantitativo de Morisita-Horn. Além disso, a análise de correspondência segmentada (DCA) foi aplicada para avaliar a substituição das espécies ao longo do espaço (gradiente ambiental). Para a realização da Análise de Agrupamento Hierárquico e da DCA foi elaborada uma matriz de densidade de indivíduos de cada espécie por parcela. Estas análises foram realizadas no software PAST 3.10 (HAMMER; HARPER; RYAN, 2001).

\section{RESULTADOS E DISCUSSÃO}

No total, foram mensurados 1.227 indivíduos, sendo 1.158 indivíduos vivos (2.316 ind.ha $\left.{ }^{-1}\right)$ e 69 indivíduos mortos em pé (138 ind.ha-1), distribuídos em 41 espécies, 28 gêneros e 22 famílias (Tabela 1). Dentre as espécies, uma foi identificada até o nível de família e quatro até o nível de gênero.

As famílias com maior riqueza foram Myrtaceae (12 espécies), Primulaceae (4) e Asteraceae (3), as quais somaram $46,3 \%$ da riqueza total da área. Estas famílias também foram as de maior riqueza em outros trabalhos realizados em Floresta Ombrófila Mista ( MAUHS, 2002; HIGUCHI et al., 2012; 2013; SILVA et al., 2012; SOUZA et al., 2012), com destaque principal para Myrtaceae, que geralmente aparece como a principal família não só nesta fitofisionomia (NASCIMENTO; LONGHI; BRENA, 2001; KLAUBERG et al., 2010; SILVA et al., 2012; PSCHEIDT et al., 2015), mas também na maioria das florestas ombrófilas localizadas acima de $1.000 \mathrm{~m}$ de altitude no sudeste do Brasil (MEIRELES; SHEPHERD; KINOSHITA, 2008; POMPEU et al., 2014). Em contrapartida, Lauraceae, também mencionada como uma das famílias mais ricas em Floresta Ombrófila Mista (RONDON-NETO et al., 2002a; 2002b; SONEGO; BACKES; SOUZA, 2007; SOUZA et al., 2012; SILVA et al., 2013) foi representada no PESP por apenas duas espécies. 
TABELA 1: Parâmetros estruturais das espécies amostradas na Floresta Ombrófila Mista Altomontana do Parque Estadual da Serra do Papagaio - Minas Gerais, Brasil. As espécies estão ordenadas de forma decrescente segundo o Valor de Importância (VI\%). Siglas - DA: densidade absoluta (ind.ha $\left.{ }^{-1}\right)$; AB: área basal $\left(\mathrm{m}^{2}\right.$. ha-1); FA: frequência absoluta (número de amostras); DR: densidade relativa (\%); DoR: dominância relativa (\%); FR: frequência relativa (\%).

TABLE 1: Structural parameters of tree species recorded in the Upper Montane Mixed Ombrophylous Forest of Parque Estadual da Serra do Papagaio - Minas Gerais state, Brazil. Species ordered in decreasing order according to Importance Value (VI\%). Abbreviations - DA: absolute density (ha-1); AB: basal area ( $\mathrm{m}^{2}$. $\mathrm{ha}^{-1}$ ); FA: absolute frequency; DR: relative density; DoR: relative dominance; FR: relative frequency.

\begin{tabular}{|c|c|c|c|c|c|c|c|c|}
\hline Espécie & Família & $\overline{\mathrm{DA}}$ & $\mathrm{AB}$ & FA & DR & DoR & FR & VI $(\%)$ \\
\hline Podocarpus lambertii Klotzsch ex Endl. & Podocarpaceae & 478 & 27,77 & 25 & 20,64 & 45,04 & 8,28 & 24,65 \\
\hline Araucaria angustifolia (Bertol.) Kuntze & Araucariaceae & 192 & 19,85 & 25 & 8,29 & 32,19 & 8,28 & 16,25 \\
\hline Myrceugenia bracteosa (DC.) D. Legrand \& Kausel & Myrtaceae & 498 & 3,54 & 25 & 21,50 & 5,74 & 8,28 & 11,84 \\
\hline Myrsine umbellata Mart. & Primulaceae & 210 & 2,13 & 22 & 9,07 & 3,46 & 7,28 & 6,60 \\
\hline Myrcia laruotteana Cambess. & Myrtaceae & 146 & 0,96 & 17 & 6,30 & 1,56 & 5,63 & 4,50 \\
\hline Ocotea pulchella (Nees\& Mart.) Mez & Lauraceae & 140 & 0,97 & 15 & 6,04 & 1,57 & 4,97 & 4,19 \\
\hline Piptocarpha regnellii (Sch.Bip.) Cabrera & Asteraceae & 78 & 1,31 & 14 & 3,37 & 2,12 & 4,64 & 3,38 \\
\hline Annona rugulosa (Schltdl.) H. Rainer & Annonaceae & 50 & 0,27 & 14 & 2,16 & 0,43 & 4,64 & 2,41 \\
\hline Cyathea corcovadensis (Raddi) Domin & Cyatheaceae & 36 & 0,79 & 9 & 1,55 & 1,29 & 2,98 & 1,94 \\
\hline Dicksonia sellowiana Hook. & Dicksoniaceae & 40 & 0,84 & 7 & 1,73 & 1,36 & 2,32 & 1,80 \\
\hline $\begin{array}{l}\text { Allophylus edulis (A.St.-Hil. et al.) Hieron. ex } \\
\text { Niederl. }\end{array}$ & Sapindaceae & 40 & 0,25 & 8 & 1,73 & 0,40 & 2,65 & 1,59 \\
\hline Drimys brasiliensis Miers & Winteraceae & 40 & 0,18 & 8 & 1,73 & 0,29 & 2,65 & 1,55 \\
\hline Myrcia pulchra (O. Berg) Kiaersk. & Myrtaceae & 22 & 0,13 & 10 & 0,95 & 0,20 & 3,31 & 1,49 \\
\hline Ilex chamaedryfolia Reissek & Aquifoliaceae & 32 & 0,19 & 8 & 1,38 & 0,31 & 2,65 & 1,45 \\
\hline Myrcia venulosa DC. & Myrtaceae & 40 & 0,17 & 7 & 1,73 & 0,28 & 2,32 & 1,44 \\
\hline Agarista oleifolia (Cham.) G. Don var. oleifolia & Ericaceae & 26 & 0,16 & 7 & 1,12 & 0,25 & 2,32 & 1,23 \\
\hline Moquiniastrum polymorphum (Less.) G. Sancho & Asteraceae & 16 & 0,42 & 6 & 0,69 & 0,67 & 1,99 & 1,12 \\
\hline Symplocos falcata Brand & Symplocaceae & 20 & 0,10 & 7 & 0,86 & 0,15 & 2,32 & 1,11 \\
\hline $\begin{array}{l}\text { Myrceugenia regnelliana (O.Berg) D. Legrand \& } \\
\text { Kausel }\end{array}$ & Myrtaceae & 32 & 0,08 & 5 & 1,38 & 0,13 & 1,66 & 1,06 \\
\hline Prunus myrtifolia (L.) Urb. & Rosaceae & 16 & 0,15 & 6 & 0,69 & 0,24 & 1,99 & 0,97 \\
\hline Myrsine gardneriana A. DC. & Primulaceae & 14 & 0,22 & 5 & 0,60 & 0,35 & 1,66 & 0,87 \\
\hline Baccharis oreophila Malme & Asteraceae & 14 & 0,09 & 5 & 0,60 & 0,15 & 1,66 & 0,80 \\
\hline Myrsine coriacea (Sw.) R.Br. ex Roem. \& Schult. & Primulaceae & 12 & 0,13 & 5 & 0,52 & 0,22 & 1,66 & 0,80 \\
\hline Mimosa scabrella Benth. & Fabaceae & 16 & 0,16 & 4 & 0,69 & 0,26 & 1,32 & 0,76 \\
\hline Jacaranda cuspidifolia Mart. & Bignoniaceae & 10 & 0,11 & 4 & 0,43 & 0,18 & 1,32 & 0,65 \\
\hline Rhamnus sphaerosperma Sw. & Rhamnaceae & 10 & 0,03 & 4 & 0,43 & 0,05 & 1,32 & 0,60 \\
\hline Styrax leprosus Hook. \& Arn. & Styracaceae & 8 & 0,04 & 4 & 0,35 & 0,06 & 1,32 & 0,58 \\
\hline Myrcia retorta Cambess. & Myrtaceae & 12 & 0,06 & 3 & 0,52 & 0,10 & 0,99 & 0,54 \\
\hline Myrtaceae 1 & Myrtaceae & 6 & 0,12 & 3 & 0,26 & 0,20 & 0,99 & 0,48 \\
\hline Myrsine cf. lancifolia Mart. & Primulaceae & 10 & 0,15 & 2 & 0,43 & 0,24 & 0,66 & 0,45 \\
\hline Miconia budlejoides Triana & $\begin{array}{l}\text { Melastomatace } \\
\text { ae }\end{array}$ & 14 & 0,04 & 2 & 0,60 & 0,06 & 0,66 & 0,44 \\
\hline Clethra scabra Pers. & Clethraceae & 6 & 0,03 & 3 & 0,26 & 0,05 & 0,99 & 0,43 \\
\hline
\end{tabular}


TABELA 1: Continuação...

TABLE 1: Continued...

\begin{tabular}{llrrrrrrr}
\hline Espécie & Família & DA & AB & FA & DR & DoR & FR & VI (\%) \\
\hline Siphoneugena crassifolia (DC.) Proença \& Sobral & Myrtaceae & 10 & 0,03 & 2 & 0,43 & 0,05 & 0,66 & 0,38 \\
& Pentaphylacac & & & & & & \\
Ternstroemia brasiliensis Cambess. & eae & 4 & 0,07 & 2 & 0,17 & 0,11 & 0,66 & 0,31 \\
Pimenta pseudocaryophyllus (Gomes) Landrum & Myrtaceae & 4 & 0,04 & 2 & 0,17 & 0,06 & 0,66 & 0,30 \\
Campomanesia sp.1 & Myrtaceae & 4 & 0,02 & 2 & 0,17 & 0,04 & 0,66 & 0,29 \\
Ilex sp.1 & Aquifoliaceae & 2 & 0,02 & 1 & 0,09 & 0,04 & 0,33 & 0,15 \\
Ocotea sp.1 & Lauraceae & 2 & 0,02 & 1 & 0,09 & 0,03 & 0,33 & 0,15 \\
Siphoneugena sp. 1 & Myrtaceae & 2 & 0,01 & 1 & 0,09 & 0,02 & 0,33 & 0,15 \\
Myrcia guianensis (Aubl.) DC. & Myrtaceae & 2 & 0,01 & 1 & 0,09 & 0,02 & 0,33 & 0,15 \\
Symplocos celastrinea Mart. & Symplocaceae & 2 & 0,01 & 1 & 0,09 & 0,01 & 0,33 & 0,14 \\
\hline
\end{tabular}

Com relação aos gêneros, os mais representativos foram Myrcia e Myrsine com cinco e quatro espécies respectivamente. Myrcia é um gênero frequentemente citado como importante na composição da Floresta Ombrófila Mista (KOZERA; DITTRICH; SILVA, 2006; HIGUCHI et al., 2012; SILVA et al., 2012). Já Myrsine não possui representatividade muito grande nesta fitofisionomia, porém, é citado por Oliveira-Filho e Fontes (2000) como fortemente associado com as florestas de altitude do sudeste brasileiro. Além disso, é considerado por Webster (1995) como um gênero típico de Florestas Nebulares Neotropicais, juntamente com outros gêneros também encontrados nas áreas de estudo, como por exemplo, Drimys, Clethra, Podocarpus e Prunus.

Foram encontradas três espécies ameaçadas de extinção: Araucaria angustifolia, Dicksonia sellowiana e Myrcengenia bracteosa, todas enquadradas na categoria "em perigo" na lista nacional (MARTINELLI; MORAES, 2013). A espécie Araucaria angustifolia também é citada na categoria "criticamente ameaçada" em escala global (INTERNATIONAL UNION FOR CONSERVATION OF NATURE, 2015). As espécies Araucaria angustifolia e Dicksonia sellowiana encontram-se sob ameaça, pois são altamente exploradas por atividades humanas (GASPER et al., 2011; MONTAGNA et al., 2012; MARTINELLI; MORAES, 2013). Já Myrceugenia bracteosa encontra-se nesta categoria pois supõe-se que sua população esteja altamente fragmentada, uma vez que as subpopulações estão muito distantes uma das outras, de maneira que o fluxo gênico entre elas pode ser praticamente nulo (MARTINELLI; MORAES, 2013; CENTRO NACIONAL DE CONSERVAÇÃO DA FLORA, 2017).

Foi observada na comunidade uma forte dominância específica, isto é, uma concentração dos valores de importância (VI) nas três primeiras espécies (Podocarpus lambertii, Araucaria angustifolia e Myrceugenia bracteosa), as quais somam 52,74\% do VI total da área. No entanto, esta dominância já era esperada, pois Podocarpus lambertii e Araucaria angustifolia são espécies que no PESP ocorrem com elevado número de indivíduos e estes, em sua maioria, com grande área basal.

Alguns trabalhos também apontaram Podocarpus lambertii entre as espécies de maior valor de importância na comunidade em florestas ombrófilas mistas (SEGER et al., 2005; SOUZA et al., 2012). A espécie foi registrada como a de maior VI mesmo em áreas de reflorestamentos com Araucaria angustifolia em Campos do Jordão-SP (RIBEIRO; MARTINS; IVANAUSKAS, 2012). Possuir essa espécie em destaque na estrutura da comunidade do PESP é relevante, pois contribui consideravelmente para a riqueza e diversidade das epífitas, como demonstrado por Furtado e Menini Neto (2015), que encontraram para este forófito riqueza e diversidade de espécies ( $\mathrm{H}^{\prime}$ ) extremamente elevadas quando comparados com estudos desenvolvidos nas regiões sul e sudeste do Brasil.

A espécie Araucaria angustifolia alcançou o segundo maior VI por ocorrer com elevada densidade, área basal e frequência, o que é relevante por se tratar de espécie ameaçada de extinção (MARTINELLI; MORAES, 2013; INTERNATIONAL UNION FOR CONSERVATION OF NATURE, 2015). Além disso, embora Araucaria angustifolia seja uma espécie comum em fragmentos de Floresta Ombrófila Mista, elevados valores de densidade e área basal para a espécie são raros na literatura, havendo apenas alguns registros para o estado do Rio Grande do Sul (RONDON-NETO et al., 2002a; SONEGO; BACKES; 
SOUZA, 2007).

Já Myrceugenia bracteosa ocorre desde o Rio Grande do Sul até Minas Gerais (THE BRAZIL FLORA GROUP, 2015), no entanto, como já mencionado, esta espécie encontra-se categorizada como ameaçada de extinção, pois suas subpopulações estão muito distantes uma das outras, dificultando o fluxo gênico entre elas, além disso, é encontrada em poucas unidades de conservação, estando sujeita à diminuição de área e de qualidade de habitat (CENTRO NACIONAL DE CONSERVAÇÃO DA FLORA, 2017). A espécie ocupou a terceira posição no ranking de VI devido ao grande número de indivíduos distribuídos por toda área de estudo, fato este bastante importante para sua conservação, uma vez que os dados de estimativa populacional para Myrceugenia bracteosa são baixos (CENTRO NACIONAL DE CONSERVAÇÃO DA FLORA, 2017). Em um trabalho desenvolvido por Carvalho, Fontes e OliveiraFilho (2000) foram encontrados apenas 14 indivíduos da espécie em uma área de aproximadamente cinco hectares, em contrapartida no presente trabalho foram amostrados 498 indivíduos em apenas um hectare.

$\mathrm{O}$ valor do índice de diversidade de espécies (H') foi de 2,67 nats.ind ${ }^{-1}$. Este valor está abaixo do padrão normalmente encontrado para fragmentos de Floresta Ombrófila Mista (Tabela 2). No entanto, quando comparado com trabalhos realizados nas formações altimontanas, o valor de $\mathrm{H}$ ' fica bem próximo à maioria destes (Tabela 2). Apesar do aspecto negativo da comparação direta entre os valores do índice de diversidade, procurou-se comparar apenas índices de diversidade obtidos em levantamentos com critérios de inclusão semelhante a este estudo. Porém, mesmo assim, esta comparação deve ser analisada com cautela, devido às variações no esforço amostral (MAGURRAN, 2012). Complementarmente, o índice de equabilidade de Pielou (J') apresentou valor de 0,72 , o que evidencia que apenas $72 \%$ da diversidade (H') hipotética máxima da área foi atingida. Este baixo valor de J'é um reflexo da dominância de um pequeno conjunto de espécies na comunidade, especialmente de Podocarpus lambertii, Araucaria angustifolia e Myrceugenia bracteosa, conforme discutido anteriormente.

A menor diversidade nas florestas de altitudes mais elevadas está associado aos rigores climáticos e edáficos que estas formações estão sujeitas (RODERJAN et al., 2002; BERTONCELLO et al., 2011). $\mathrm{O}$ clima frio, atrelado à presença frequente de geadas, neblina e rajadas de ventos, acaba limitando o estabelecimento de algumas espécies. Corroborando este fato, um estudo desenvolvido nas florestas montanas dos Andes, Gentry (1993) verificou alta correlação entre a diminuição da diversidade de espécies e o aumento da altitude (acima de 1.500 m.s.m.). Além dos rigores climáticos associados à altitude, por ser uma floresta que acompanha o fluxo de um córrego, em alguns períodos do ano sofre também com extrema umidade (mesmo que a área não sofra alagamento), desta forma, o menor valor encontrado na diversidade de espécies (H') pode estar associado também à restrição ambiental imposta pela saturação hídrica do solo (IVANAUSKAS; RODRIGUES; NAVE, 1997).

A comunidade apresentou área basal total de $30,82 \mathrm{~m}^{2}\left(61,65 \mathrm{~m}^{2} . \mathrm{ha}^{-1}\right)$ e surpreendeu por se diferenciar das demais Florestas Ombrófilas Mistas por ser a localidade com maior acúmulo de área basal dentre aquelas com maior densidade de indivíduos (Figura 1, Tabela 2). Observa-se para o PESP que o maior acúmulo de biomassa (área basal) está relacionado à grande concentração de indivíduos nas últimas classes de diâmetro (Figura 2), que são representadas principalmente pelos indivíduos de Araucaria angustifolia e Podocarpus lambertii. A importância destas duas espécies na fisionomia e estrutura da Floresta Ombrófila Mista foi destacada por Behling e Pillar (2007) e Carlucci et al. (2011). Sabe-se que Podocarpus lambertii tende a atingir porte elevado em florestas maduras (SOUZA et al., 2012), assim como a Araucaria angustifolia atinge grandes diâmetros em florestas sem histórico de perturbação (SOUZA et al., 2008).

Sabendo que a área basal de uma comunidade tende a aumentar com a idade da floresta (CHAZDON, 2008; LEBRIJA-TREJOS et al., 2010), pode-se então inferir que florestas mistas subtropicais maduras tendem a apresentar elevada área basal (valores acima de $40 \mathrm{~m}^{2} \cdot \mathrm{ha}^{-1}$ ), mas associada a valores de densidade entre 1.500 e 1.800 ind.ha $^{-1}$, de modo a permitir o desenvolvimento de árvores de grande porte de suas populações típicas (Figura 2). Nesse contexto, pode-se afirmar que a floresta estudada encontra-se em estágio avançado de sucessão ecológica, mas ainda com densidade total acima do esperado para uma floresta madura dessa fitofisionomia. Esta informação é de extrema importância para o parque, pois reforça ainda mais a importância desta Unidade de Conservação em Minas Gerais, que resguarda uma fitofisionomia tão ameaçada e rara no país (BAUERMANN; BEHLING, 2009; CARLUCCI et al., 2011).

Ci. Fl., v. 28, n. 2, abr. - jun., 2018 


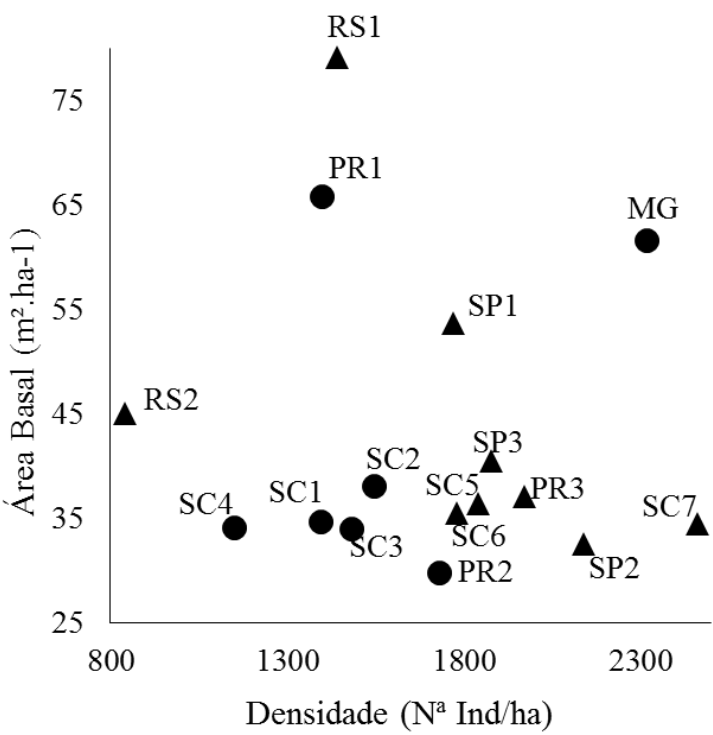

FIGURA 1: FIGURA 1: Relação entre densidade $\left(\mathrm{N}^{\circ}\right.$ ind.ha-1) e área basal $\left(\mathrm{m}^{2} . h a-1\right)$ de trabalhos realizados em fragmentos de Floresta Ombrófila Mista no Brasil. Siglas das localidades de acordo com a Tabela 2. Símbolos: Floresta Ombrófila Mista Altomontana; $\mathbf{\Delta}$ Floresta Ombrófila Mista Montana. Área de estudo $=$ MG

FIGURE 1: FIGURE 1: Correlation between density $\left(\mathrm{N}^{\circ}\right.$ ind.ha-1) and basal area $\left(\mathrm{m}^{2}\right.$.ha-1) of studies done in Mixed Ombrophylous Forest fragments in Brazil. Abbreviations of locations are according to Table 2. Symbols: U Upper Montane Mixed Ombrophylous Forest; $\Delta$ Montane MixedOmbrophylous Forest. Study area $=$ MG.

TABELA 2: Respectivos valores de área basal, número de indivíduos, diversidade de espécies ( $\left.\mathrm{H}^{\prime}\right)$, área amostral, critério de inclusão, estado e altitude em trabalhos desenvolvidos em Floresta Ombrófila Mista no Brasil. Tabela ordenada de forma decrescente, segundo a altitude por estado. Sigla: DAP = limite de inclusão de diâmetro a altura do peito. * Floresta Ombrófila Mista Aluvial.

TABLE 2: Areas of Mixed Ombrophylous Forest compared in the study with their basal area, number of individuals, species diversity ( $\left.\mathrm{H}^{\prime}\right)$, sample area, inclusion criteria, state and altitude. Table sorted in decreasing order according to the basal area value. Abbreviations: DAP = diameter at breast height * Alluvial Mixed Ombrophylous Forest.

\begin{tabular}{|c|c|c|c|c|c|c|c|}
\hline Estudo & $\begin{array}{c}\text { Área } \\
\text { Basal } \\
\left(\mathrm{m}^{2} \cdot \mathrm{ha}^{-1}\right)\end{array}$ & $\begin{array}{c}\text { N. de } \\
\text { Indivíduos } \\
\left(\mathrm{N} . \text { Ind.ha }^{-1}\right)\end{array}$ & $\mathrm{H}^{\prime}$ & $\begin{array}{c}\text { Área } \\
\text { amostral } \\
\text { (ha) }\end{array}$ & $\begin{array}{c}\text { DAP de } \\
\text { inclusão } \\
(\mathrm{cm})\end{array}$ & Município - Estado (Sigla) & $\begin{array}{l}\text { Altitude } \\
\text { (m.s.m) }\end{array}$ \\
\hline Área de estudo* & 61,66 & 2.316 & 2,67 & 0,50 & $\geq 4,8$ & Baependi - MG (MG) & 1.700 \\
\hline SOUZA et al. $2012^{*}$ & 53,60 & 1.770 & 3,08 & 1,00 & $\geq 4,8$ & Campos do Jordão - SP (SP1) & 1.467 \\
\hline RIBEIRO et al. 2013 & 32,49 & 2.142 & - & 0,86 & $\geq 4,8$ & Bananal - SP (SP2) & 1.174 \\
\hline SOUZA, 2008 & 40,50 & 1.879 & 3,81 & 1,00 & $\geq 4,8$ & Barra do Chapéu - SP (SP3) & 1.000 \\
\hline $\begin{array}{l}\text { CORDEIRO; RODRIGUES, } \\
2007\end{array}$ & 65,78 & 1.397 & 2,79 & 0,32 & $\geq 4,8$ & Guarapuava - PR (PR1) & 1.070 \\
\hline LIMA et al. 2012 & 29,82 & 1.728 & 2,40 & 0,28 & $\geq 4,8$ & Guarapuava - PR (PR2) & 1.083 \\
\hline RONDON-NETO et al. $2002 \mathrm{~b}$ & 37,08 & 1.972 & 3,43 & 0,36 & $\geq 5,0$ & Curitiba - PR (PR3) & 900 \\
\hline HIGUCHI et al. 2013 & 34,80 & 1.395 & 2,79 & 1,00 & $\geq 5,0$ & Painel - SC (SC1) & 1.399 \\
\hline $\begin{array}{l}\text { PSCHEIDT et al. } 2015 \\
\text { (Interior) }\end{array}$ & 38,18 & 1.546 & 3,51 & 0,50 & $\geq 5,0$ & Lages - SC (SC2) & 1.080 \\
\hline $\begin{array}{l}\text { PSCHEIDT et al. } 2015 \\
\text { (Borda) }\end{array}$ & 34,06 & 1.482 & 3,35 & 0,50 & $\geq 5,0$ & Lages - SC (SC3) & 1.080 \\
\hline KLAUBERG et al. 2010 & 34,20 & 1.150 & 3,05 & 0,64 & $\geq 5,0$ & Lages - SC (SC4) & 1.020 \\
\hline HIGUCHI et al. 2012 & 36,45 & 1.843 & 3,74 & 1,00 & $\geq 5,0$ & Lages - SC (SC5) & 990 \\
\hline SILVA et al. 2012 & 35,54 & 1.783 & 3,60 & 1,00 & $\geq 5,0$ & Lages - SC (SC6) & 916 \\
\hline SILVA et al. $2013^{*}$ & 34,45 & 2.462 & - & 0,40 & $\geq 5,0$ & Alfredo Wagner - SC (SC7) & 800 \\
\hline SONEGO et al. 2007 & 79,05 & 1.444 & 2,95 & 0,29 & $\geq 5,0$ & $\begin{array}{c}\text { São Francisco de Paula - RS } \\
\text { (RS1) }\end{array}$ & 923 \\
\hline RONDON-NETO et al. 2002a & 45,01 & 842 & 2,76 & 0,80 & $\geq 5,0$ & Criúva - RS (RS2) & 860 \\
\hline
\end{tabular}




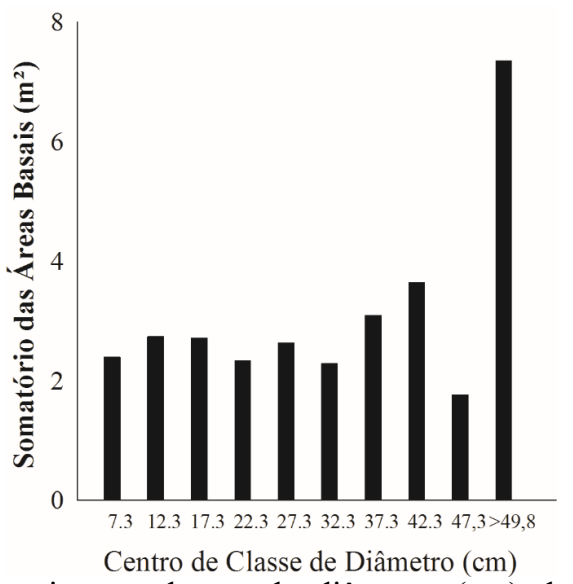

FIGURA 2: Somatório das áreas basais por classes de diâmetro $(\mathrm{cm})$ da comunidade amostrada na Floresta Ombrófila Mista Altomontana do Parque Estadual da Serra do Papagaio - Minas Gerais, Brasil.

FIGURE 2: $\quad$ Sum of basal areas by diameter class $(\mathrm{cm})$ of community recorded in the Upper Montane Mixed Ombrophylous Forest of Parque Estadual da Serra do Papagaio - Minas Gerais state, Brazil.

Por meio de análises multivariadas constatou-se a baixa heterogeneidade florística na comunidade, consequência do ambiente bastante seletivo para espécies tolerantes às condições microclimáticas de elevadas altitudes. Levando em consideração o limite de divisão significativo para florestas heterogêneas de 0,5 (FELFILI et al., 2011), a similaridade, utilizando o método de agrupamento, apresentou a maioria das ligações entre as unidades amostrais acima deste valor (Figura 3), o que demonstra forte afinidade florística entre as parcelas. Esta baixa heterogeneidade reflete a adaptação das espécies ao ambiente, pois as populações mais abundantes são também as mais frequentes, com indivíduos distribuídos por toda a floresta. De forma complementar, a análise de correspondência distendida (DCA) apresentou um gradiente ambiental relativamente fraco (Figura 4), com autovalor dentro do limite significativo apenas no eixo 1 (Eixo $1=0,31$; Eixo $2=0,19$ ), considerando o conceito de autovalor significativo $>0,3$ (FELFILI et al., 2011). O fraco gradiente ambiental encontrado na DCA pode ser igualmente explicado pelo fato de um pequeno grupo de espécies ocupar a maior parte do nicho fundamental da área, com apenas uma minoria das espécies concentrando-se em nichos menores no gradiente (KENT; COKER, 1992). Exceção ocorreu na Parcela 4 (P4) que, apesar de ter as mesmas características ambientais das outras parcelas, apresentou composição florística distinta das demais tanto na análise de agrupamento quanto na DCA (Figuras 3 e 4 ) em função da menor riqueza, pois Myrcia venulosa e Agarista oleifolia ocorreram nesta parcela com maior número de indivíduos quando comparado às demais parcelas, restringindo o estabelecimento de outras espécies.

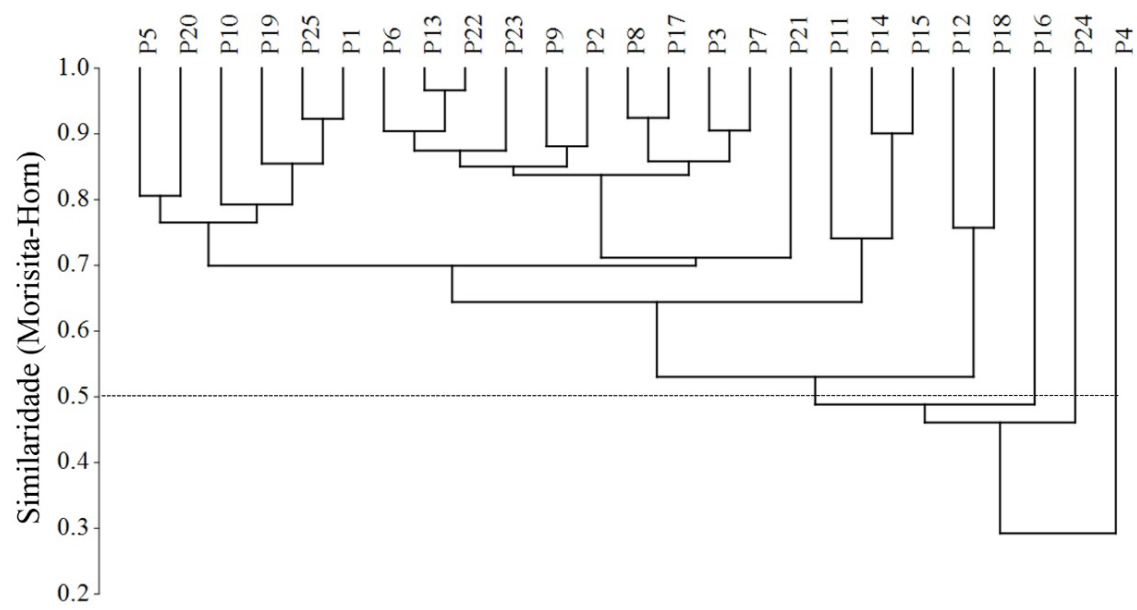

FIGURA 3: Análise de agrupamento de espécies entre as parcelas pelo coeficiente de Morisita-Horn (quantitativo); correlação cofenética $=0,8622$. Método de agrupamento: UPGMA.

FIGURE 3: Species cluster analysis between plots by Morisita-Horn coefficient (quantitative); cophenetic correlation $=0,8622$. Clustering method: UPGMA. 


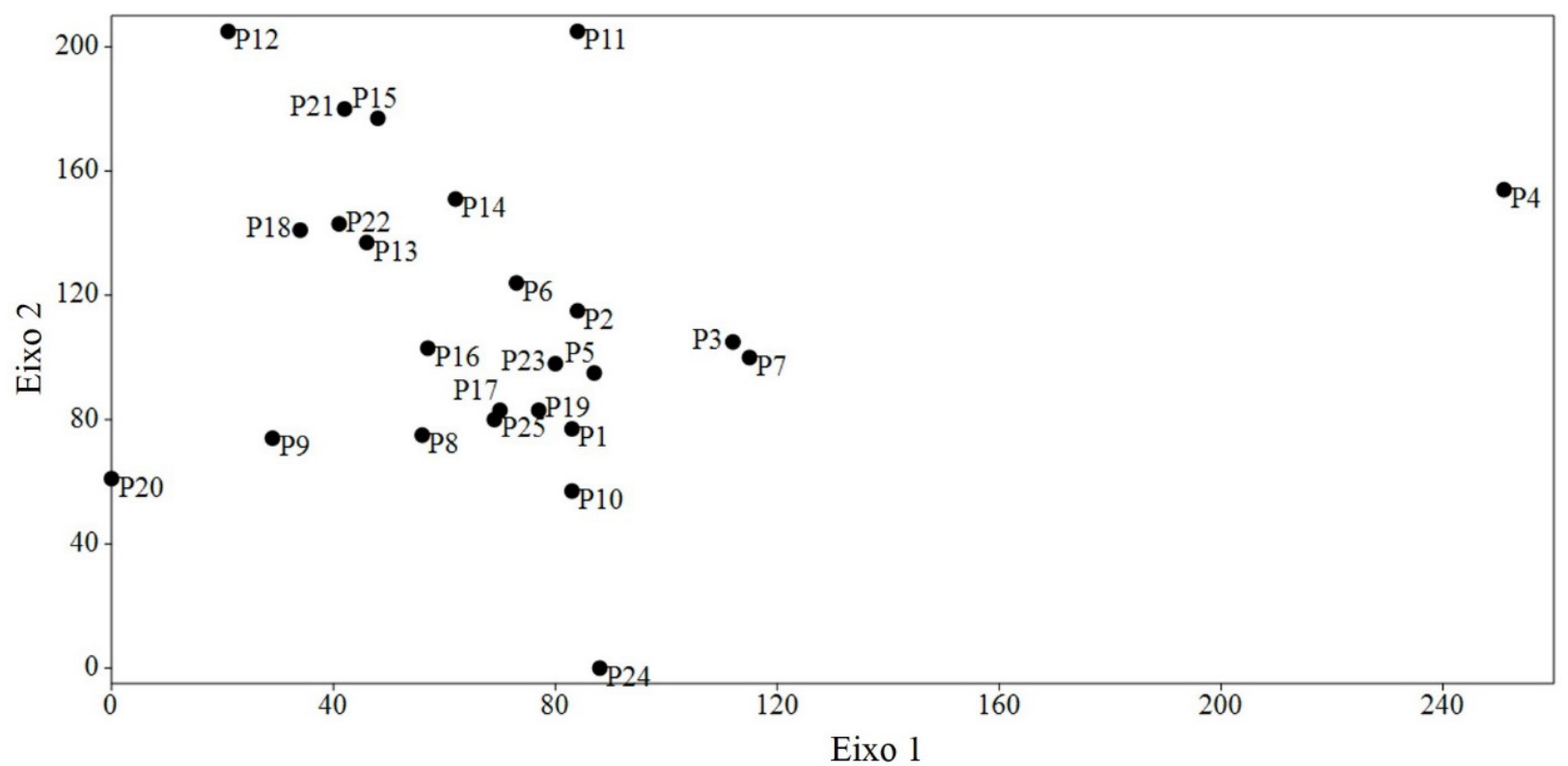

FIGURA 4: Diagrama de ordenação das parcelas resultante da Análise da correspondência segmentada (DCA). FIGURE 4: Diagram of plots ordination from the detrended correspondence analysis (DCA).

\section{CONCLUSÕES}

Este trabalho trata do estudo mais setentrional e em maior altitude já descrito para Floresta Ombrófila Mista, revelando uma comunidade em estágio avançado de sucessão ecológica cuja área basal está entre as maiores já registradas para esta fitofisionomia. O maior acúmulo de biomassa (área basal) está concentrado nas classes de diâmetro mais elevadas, provenientes das populações de Araucaria angustifolia e Podocarpus lambertii. O clima subtropical, típico das elevadas altitudes da região Sudeste do Brasil, e o condicionamento ao ambiente aluvial, são fatores seletivos que contribuem para a baixa diversidade de espécies encontrada. A floresta apresentou alta dominância ecológica, revelada pela concentração dos valores de importância nas três primeiras espécies (Podocarpus lambertii, Araucaria angustifolia e Myrceugenia bracteosa). A presença de floresta com araucária em avançado estádio de sucessão salienta a importância do Parque Estadual da Serra do Papagaio para a conservação desta fisionomia e o estabelecimento de planos de ação que permitam a existência de populações viáveis das espécies ameaçadas ali presentes.

\section{AGRADECIMENTOS}

Este trabalho é resultante da Dissertação de Mestrado do primeiro autor junto ao Programa de Pós-graduação em Ecologia da Universidade Federal de Juiz de Fora (PGECOL-UFJF). Agradecemos ao PGECOL-UFJF pelo apoio logístico; à equipe do Laboratório de Ecologia Vegetal e do herbário CESJ (UFJF) pela ajuda nos trabalhos de campo; aos taxonomistas Andressa Cabral, Kelly Antunes, Miltom Groppo Jr., Luciana L. Justino, e Vinícius A. O. Dittrich, pela identificação das Ericaceae, Myrtaceae, Aquifoliaceae, Melastomataceae e Samambaias, respectivamente; ao IEF/MG e aos funcionários do PESP pela logística, em especial Clarice Silva e Emanuel Landroz; ao CNPq (Processo: 454008/2014-7) e a FAPEMIG (Processo: APQ 2165/14) pelo apoio financeiro; a CAPES pela concessão da bolsa de Mestrado ao primeiro autor.

\section{REFERÊNCIAS}

ALMEIDA, F. F. M. A.; CARNEIRO, D. R. C. Origem e evolução da Serra do Mar. Revista Brasileira de Geociências, Porto Alegre, v. 28, n. 2, p. 135-150, 1998.

ANGIOSPERM PHYLOGENY GROUP IV. An update of the Angiosperm Phylogeny Group classification 
for the orders and families of flowering plants: APG IV. Botanical Journal of the Linnean Society, London, v. 181, p. 1-20, 2016.

BAUERMANN, S. G.; BEHLING, H. Dinâmica paleovegetacional da Floresta com Araucária a partir do final do Pleistoceno: o que mostra a palinologia. In: RAMOS-COSTA, A. M. M. et al. (Ed.). Floresta com Araucária - Ecologia, Conservação e Desenvolvimento Sustentável. Ribeirão Preto: Holos, 2009. p. 35-38.

BEHLING, H.; PILLAR, V. D. Late quaternary vegetation, biodiversity and fire dynamics on the Southern Brazilian highland and their implication for conservation and management of modern Araucaria forest and grassland ecosystems. Philosophical Transactions of the Royal Society B: Biological Sciences, London, v. 362, n. 1478, p. 243-251, 2007.

BERTONCELLO, R. et al. A phytogeographic analysis of cloud forests and other forest subtypes amidst the Atlantic forests in south and southeast Brazil. Biodiversity and Conservation, London. v. 20, n. 14, p. 3413-3433, 2011.

CARLUCCI, M. B. et al. Conservação da Floresta com Araucária no extremo Sul do Brasil. Natureza e Conservação, Rio de Janeiro, v. 9, n. 1, p. 111-114, 2011.

CARVALHO, L. M. T.; FONTES, M. A. L.; OLIVEIRA-FILHO, A. T. Tree species distribution in canopy gaps and mature forest in an area of cloud forest of the Ibitipoca Range, south-eastern Brazil. Plant Ecology, Netherlands, v. 149, n. 1, p. 9-22, 2000.

CENTRO NACIONAL DE CONSERVAÇÃO DA FLORA (Brasil). Myrceugenia bracteosa in Lista Vermelha da flora brasileira versão 2012.2. Rio de Janeiro: CNCFlora, 2017. Disponível em: <http:// cncflora.jbrj.gov.br/portal/pt-br/profile/Myrceugenia bracteosa $>$. Acesso em: 3 mar. 2017.

CHAZDON, R. L. Chance and determinism in tropical forest sucession. In: CARSON, W. P.; SCHNITZER, S. A. (Ed.). Tropical Forest Community Ecology. Chichester: Blackwell, 2008. p. 384-408.

CORDEIRO, J.; RODRIGUES, W. A. Caracterização fitossociológica de um remanescente de Floresta Ombrófila Mista em Guarapuava, PR. Revista Árvore, Viçosa, MG, v. 31, n. 3, p. 545-554, 2007.

COSTA, C.; HERMANN, G. O corredor Ecológico da Mantiqueira. In: COSTA, C. M. R. et al. (Ed.). Plano de ação do corredor Ecológico da Mantiqueira. Belo Horizonte: Valor Natural, 2006. p. 13-25.

FELFILI, J. M. et al. Análise multivariada: princípios e métodos em estudos de vegetação. In: FELFILI, J. M. et al. (Ed.). Fitossociologia no Brasil: métodos e estudos de casos. Viçosa, MG: Editora UFV, 2011. p. 122-155.

FURTADO, S. G.; MENINI NETO, L. Vascular epiphytic flora of a high montane environment of Brazilian Atlantic Forest: composition and floristic relationships with other ombrophilous forests. Acta Botanica Brasilica, Belo Horizonte, v. 30, n. 3, p. 422-436, 2016.

GASPER, A. L. et al. Inventário de Dicksonia sellowiana Hook. em Santa Catarina. Acta Botanica Brasilica, Feira de Santana, v. 25, n. 4, p. 776-784, 2011.

GENTRY, A. H. Patterns of diversity and floristic composition in Neotropical Montane Forests. In: CHURCHILL, S. P. et al. (Ed.). Biodiversity and conservation of Neotropical montane forests. New York: The New York Botanical Garden, 1993. p. 103-126.

HAMMER, O.; HARPER, D. A. T.; RYAN, P. D. Paleontological statistics software package for education and data analysis. Palaeontologia Electronica, Oslo, v. 4, n. 1, p. 9-18, 2001.

HIGUCHI, P. et al. Influência de variáveis ambientais sobre o padrão estrutural e florístico do componente arbóreo, em um fragmento de floresta ombrófila mista montana em Lages, SC. Ciência Florestal, Santa Maria, v. 22, n. 1, p. 79-90, 2012.

HIGUCHI, P. et al. Florística e estrutura do componente arbóreo e análise ambiental de um fragmento de Floresta Ombrófila Mista Alto-Montana no município de Painel, SC. Ciência Florestal, Santa Maria, v. 23, n. 1, p. 153-164, 2013.

IBGE. Manual Técnico da Vegetação Brasileira. Rio de Janeiro: IBGE, 2012.

INSTITUTO estadual De Florestas (MG). Plano de Manejo do Parque Estadual da Serra do Papagaio. Belo Horizonte: IEF, 2009. Disponível em: <http://www.ief.mg.gov.br/images/stories/Plano de_Manejo/serra papagaio/encarte i.pdf>. Acesso em: 22 dez. 2015.

INSTITUTO ESTADUAL DE FloReStAS (MG). Parque Estadual da Serra do Papagaio. [2015]. Disponível em: <http://www.ief.mg.gov.br/areas-protegidas/211?task=view>. Acesso em: 22 dez. 2015. 
INTERNATIONAL UNION FOR CONSERVATION OF NATURE. The IUCN Red List of Threatened Species. Version 2015.4. [2015]. Disponível em: <http://www.iucnredlist.org>. Acesso em: 5 jan. 2016. IVANAUSKAS, N. M.; RODRIGUES, R. R.; NAVE, A. G. Aspectos ecológicos de um trecho de floresta de brejo em Itatinga, SP: florística, fitossociologia e seletividade de espécies. Revista Brasileira de Botânica, São Paulo, v. 20, n. 2, p. 139-153, 1997.

KENT, M.; COKER, P. Vegetation description and analysis : a practical approach. London: Belhaven P, 1992.

KERSTEN, R. A.; BORGO, M.; GALVÃO, F. Floresta Ombrófila Mista: aspectos fitogeográficos, ecológicos e métodos de estudo. In: EISENLOHR, P. V. et al. (Ed.). Fitossociologia no Brasil: métodos e estudos de casos. Viçosa, MG: Editora UFV, 2015. v. 2. p. 156-182.

KLAUBERG, C. et al. Florística e estrutura de um fragmento de Floresta Ombrófila Mista no Planalto Catarinense. Biotemas, Santa Catarina, v. 23, n. 1, p. 35-47, 2010.

KOCH, Z.; CORRÊA, M. C. Araucária: a floresta do Brasil Meridional. 2. ed. Curitiba: Olhar Brasileiro, 2010.

KOTTEK, M.; GRIESER, J.; BECK, C.; RUDOLF, B.; RUBEL, F. World Map of the Köppen-Geiger climate classification updated. Meteorologische Zeitschrift, Stuttgart, v. 15, n. 3, p. 259-263, 2006.

KOZERA, C.; DITTRICH, V. A. O.; SILVA, S. M. Fitossociologia do componente arbóreo de um fragmento de Floresta Ombrófila Mista Montana, Curitiba, PR, BR. Floresta, Curitiba, v. 36, n. 2, p. 225-237, 2006.

LE SAOUT, S. et al. Conservation. Protected areas and effective biodiversity conservation. Science, New York, v. 342, n. 6160, p. 803-805, 2013.

LEBRIJA-TREJOS, E. et al. Pathways, mechanisms and predictability of vegetation change during tropical dry forest succession. Perspectives in Plant Ecology, Evolution and Systematics, Amsterdam, v. 12, p. 267-275, 2010.

LIMA, T. E. O. et al. Caracterização fitossociológica da vegetação no entorno de nascentes de um fragmento de Floresta Ombrofila Mista Montana na bacia do rio das Pedras, Guarapuava (PR). Ambiência, Guarapuava, v. 8, n. 2, p. 229-244, 2012.

MAGURRAN, A. E. Medindo a Diversidade Biológica. Paraná: Editora UFPR, 2012.

MARTINELLI, G.; MORAES, M. A. Livro vermelho da flora do Brasil. Rio de Janeiro: Instituto de Pesquisas Jardim Botânico do Rio de Janeiro, 2013.

MAUHS, J. Fitossociologia e regeneração natural de um fragmento de floresta ombrófila mista exposto a perturbações antrópicas. 2002. 65 f. Dissertação (Mestrado em Biologia: Diversidade e Manejo de Vida Silvestre) - Universidade do Vale do Rio dos Sinos, São Leopoldo, 2002.

MEIRELES, L. D.; SHEPHERD, G. J.; KINOSHITA, L. S. Variações na composição florística e na estrutura fitossociológica de uma Floresta Ombrófila Densa Alto-montana na Serra da Mantiqueira, Monte Verde, MG. Revista Brasileira de Botânica, São Paulo, v. 31, n. 4, p. 559-574, 2008.

MONTAGNA, T. et al. A importância das Unidades de Conservação na manutenção da diversidade genética de Araucária (Araucaria angustifolia) no estado de Santa Catarina. Biodiversidade Brasileira, Brasília, v. 2, n. 2, p. 18-25, 2012.

NASCIMENTO, A. R. T.; LONGHI, J. S.; BRENA, D. A. Estrutura e padrões de distribuição espacial de espécies arbóreas em uma amostra de Floresta Ombrófila Mista em Nova Prata, RS. Ciência Florestal, Santa Maria, v. 11, n. 1, p. 105-119, 2001.

OLIVEIRA-FILHO, A. T.; FONTES, M. A. L. Patterns of floristic differentiation among Atlantic Forests in Southeastern Brazil and the influence of climate. Biotropica, Florida, v. 32, p. 793-810, 2000.

BAEPENDI (MG). Prefeitura. Dados gerais. [2015]. Disponível em: <http://www.baependi.mg.gov. br/?page_id=69>. Acesso em: $22 \mathrm{dez} .2015$.

POLISEL, R. T. et al. Structure of the understory community in four stretches of Araucaria forest in the state of São Paulo, Brazil. Acta Botanica Brasilica, Belo Horizonte, v. 28, n. 1, p. 86-101, 2014.

POMPEU, P. V. et al. Floristic composition and structure of an Upper Montane cloud forest in the Serra da Mantiqueira Mountain Range of Brazil. Acta Botanica Brasilica, Belo Horizonte, v. 28, n. 3, p. 456-464, 2014.

PSCHEIDT, F. et al. Variações Florístico-Estruturais da comunidade arbórea associadas à distância da borda em um fragmento florestal no Planalto Sul-Catarinense. Floresta, Curitiba, v. 45, n. 2, p. 421-430, 2015.

Ci. Fl., v. 28, n. 2, abr. - jun., 2018 
PTERIDOPHYTE PHYLOGENY GROUP I. A community-derived classification for extant lycophytes and ferns. Journal of Systematics and Evolution, Beijing, v. 54, n. 6, p. 563-603, 2016.

RIBEIRO, T. M. et al. Fitossociologia de uma floresta secundária com Araucaria angustifolia (Bertol.) O. Kuntze na Estação Ecológica de Bananal, Bananal, SP. Floresta e Ambiente, Seropédica, v. 20, n. 2, p. 159-172, 2013.

RIBEIRO, T. M.; MARTINS, S. V.; IVANAUSKAS, N. M. Restauração florestal com Araucaria angustifolia (Bertol.) Kuntze no parque estadual de Campos do Jordão, SP: efeito do fogo na estrutura do componente arbustivo-arbóreo. Scientia Forestalis, Piracicaba, v. 40, n. 94, p. 279-290, 2012.

RODERJAN, C. V. et al. As unidades fitogeográficas do Estado do Paraná, Brasil. Ciência e Ambiente, Santa Maria, v. 24, n. 1, p. 75-92, 2002.

RONDON-NETO, R. M. et al. Análise florística e estrutural de um fragmento de Floresta Ombrófila Mista Montana, situado em Criúva, RS - Brasil. Ciência Florestal, Santa Maria, v. 12, n. 1, p. 29-37, 2002a.

RONDON-NETO, R. M. et al. Caracterização florística e estrutural de um fragmento de Floresta Ombrófila Mista, em Curitiba, PR - Brasil. Floresta, Curitiba, v. 32, n. 1, p. 3-16, 2002 b.

SEGER, C. D. et al. Levantamento florístico e análise fitossociológica de um remanescente de floresta ombrófila mista localizado no município de Pinhais, Paraná-Brasil. Floresta, Curitiba, v. 35, n. 2, p. 291-302, 2005.

SILVA, A. C. et al. Relações florísticas e fitossociologia de uma Floresta Ombrófila Mista Montana secundária em Lages, Santa Catarina. Ciência Florestal, Santa Maria, v. 22, n. 1, p. 193-206, 2012.

SILVA, A. C. et al. Caracterização fitossociológica e fitogeográfica de um trecho de floresta ciliar em Alfredo Wagner, SC, como subsídio para restauração ecológica. Ciência Florestal, Santa Maria, v. 23, n. 4, p. 579-593, 2013.

SILVA, L. V. C.; VIANA, P. L.; MOTA, N. F. O. Plano de Manejo do Parque Estadual Serra do Papagaio, Minas Gerais, Brasil: diagnóstico cobertura vegetal. Belo Horizonte: [s. n.], 2008.

SONEGO, R. C.; BACKES, A.; SOUZA, A. F. Descrição da estrutura de uma Floresta Ombrófila Mista, RS, Brasil, utilizando estimadores não-paramétricos de riqueza e rarefação de amostras. Acta Botanica Brasilica, Feira de Santana, v. 21, n. 4, p. 943-955, 2007.

SOUZA, A. F. et al. Regeneration patterns of a long-lived dominant conifer and the effects of logging in southern South America. Acta Oecologica, Paris, v. 34, n. 2, p. 221-232, 2008.

SOUZA, R. P. M. Estrutura da comunidade arbórea de trechos de florestas de Araucaria no estado de São Paulo, Brasil. 2008. 101 f. Dissertação (Mestrado em Recursos Florestais) - Escola Superior de Agricultura Luiz de Queiroz, Piracicaba, 2008.

SOUZA, R. P. M. et al. Estrutura e aspectos da regeneração natural de Floresta Ombrófila Mista no Parque Estadual de Campos do Jordão, SP, Brasil. Hoehnea, São Paulo, v. 39, n. 3, p. 387-407, 2012.

THE BRAZIL FLORA GROUP, T. B. F. G. Growing knowledge: an overview of Seed Plant diversity in Brazil. Rodriguesia, Rio de Janeiro, v. 66, n. 4, p. 1085-1113, 2015.

WEBSTER, G. L. The panorama of Neotropical cloud forests. In: CHURCHILL, S. P. et al. (Ed.). Biodiversity and conservation of Neotropical montane forests. New York: The New York Botanical Garden, 1995. p. 53-77. 